\title{
A IMPORTÂNCIA DA AFETIVIDADE NAS SÉRIES FINAIS DO ENSINO FUNDAMENTAL: UMA ANÁLISE BIBLIOGRÁFICA
}

\section{THE IMPORTANCE OF EFFECTIVENESS IN FINAL SCHOOL SERIES: A BIBLIOGRAPHIC ANALYSIS}

Cássia Marta Felix Alves de Araújo ${ }^{1}$

Diógenes José Gusmão Coutinho²

\begin{abstract}
RESUMO: Esta pesquisa fundamenta-se na análise bibliográfica com a contribuição de diversas áreas do conhecimento que convergem para a temática em comento, buscando trazer preceitos que conceituam e estruturam - papel da afetividade nos âmbitos educacionais, psicológicos, sociais e jurídicos. O objetivo aqui destacado é a análise profunda de como esse sentimento atua na conjuntura social humana, e como o corpo docente, como guia institucional, também pode desempenhar funções no desenvolvimento intelectual fazendo uso das técnicas baseadas na individualização e particularidades de cada educando, sendo todas fundamentas no desenvolvimento do princípio da confiança gerada através do afeto. Inicialmente foram analisados os estudos que levaram à constatação de que o vínculo afetivo em sala de aula é benéfico para corpos docentes e discentes, e após tal verificação, foram desenvolvidos os tópicos inerentes aos mais diversos aspectos da temática aqui abordada. Como resultado, verificou-se que a afetividade realmente é um fator relevante que exerce influência na aprendizagem das crianças, visto que a afetividade é um das ferramentas que influenciam esse processo de ensino-aprendizagem.
\end{abstract}

Palavras-chave: Psicologia. Contexto Pedagógico. Afetividade.

ABSTRACT: This research is based on the bibliographical analysis with the contribution of several areas of knowledge that converge to the theme under discussion, seeking to bring precepts that conceptualize and structure the role of affectivity in the educational, psychological, social and legal spheres. The objective highlighted here is the deep analysis of how this feeling acts in the human social conjuncture, and how the faculty, as an institutional guide, can also perform functions in the intellectual development making use of the techniques based on the individualization and particularities of each student.

\footnotetext{
${ }^{1}$ Graduada em Licenciatura em Artes Cênicas pela Universidade Federal de Pernambuco (UFPE); especialista em Gestão Educacional pela Escola Superior Aberta do Brasil (ESAB); e mestranda em Ciências da Educação pela Faculdade Atenas College University. E-mail: kika_araujo_@hotmail.com.

2 Graduado em Biologia pela UFPE.Doutor em Biologia pela UFPE.Professor do Mestrado em Ciências da Educação pela Faculdade ALPHA. E-mail: alphadiogenes@gmail.com.
} 


\section{Universidade do Extremo Sul Catarinense \\ Revista lbero-Americano de Humanidades, Ciências e \\ Educação}

UneSC Produção e democratização do conhecimento na llbero-América

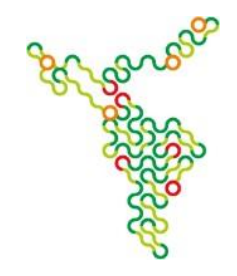

grounds for developing the principle of trust generated through affection. Initially, the studies that led to the realization that the affective bond in the classroom is beneficial to faculty and students were analyzed, and after such verification the topics inherent to the most diverse aspects of the theme addressed here were developed. As a result, it was found that affectivity is indeed a relevant factor that influences children's learning, since affectivity is one of the tools that influence this teaching-learning process.

Key words: Psychology. Pedagogical context. Affectivity.

\section{INTRODUÇÃO}

Segundo a Psicologia, a afetividade é um laço eminentemente criado entre humanos que se caracteriza pela demonstração de emoções e sentimentos a outro ser ou objetos. É um estado psicológico definido por uma variedade de impulsos emocionais que se manifestam sob a forma de amizade profunda, benquerer e paixões, acompanhados sempre da impressão de dor ou prazer de satisfação ou insatisfação, de agrado ou desagrado, de alegria ou de tristeza. São sentimentos que não podem ser dominados pelas pessoas, já que embora possam sentir tais emoções, não existe um modo de controlá-las.

A afetividade está diretamente ligada à formação do caráter do ser humano. Esse sentimento, quando vivenciado, determina o modo como as pessoas visualizam o mundo em que vivem assim como permite desenvolver apego aos entes com os quais convivem, dando a elas a capacidade de considerar a importância que possuem em suas vidas ou não, dessa forma definindo a maneira com a qual as pessoas manifestam-se no seu meio social.

Os sentimentos afetivos exercem uma influência direta nas nossas decisões durante todas as fases da vida, pois a afetividade funciona como o entusiasmo que existe dentro das pessoas determinando quais atividades um sujeito desenvolverá interesse ao longo de sua vida, no campo profissional ou pessoal, sendo o combustível para desempenhar tais funções. Desde a infância de uma pessoa já se pode perceber seu entusiasmo para algumas atividades e seu desânimo para outras e esse é um impulso inicial que provém de nossos sentimentos sendo que, esse sentimento em específico, deve ser estimulado e valorizado, pois essa etapa é a principal para a aprendizagem dos 


\section{Universidade do Extremo Sul Catarinense \\ Revista lbero-Americano de Humanidades, Ciências e \\ Educação \\ Unesc Produção e democratização do conhecimento na lbero-América}

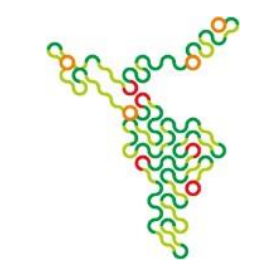

seres humanos. Nessa fase também devemos aprender a controlar nossas emoções buscando o equilíbrio.

Esse presente estudo apresenta a importância da afetividade nas séries finais do ensino fundamental, visto que a afetividade é considerada como um dos fatores a ser desenvolvido na relação entre aluno e professor, tão importante para a aprendizagem, pois o cognitivo e o emocional precisam estar em sintonia. O professor, ao utilizar estratégicas pedagógicas específicas, exerce uma postura de facilitador.

Foram abordados também os conceitos e a relevância da afetividade na vida humana, apresentando seu contexto histórico e como se dá essa interação entre educando e educador nesta etapa de ensino. Apresentou-se também a interferência dessa prática tanto nas dimensões psicológicas e cognitivas da aprendizagem.

\section{Histórico do estudo da afetividade da área psicopedagógica}

Desde o final do século XIX, vem acontecendo uma grande transformação no sentido de modificar a pedagogia tradicionalista reconhecendo um modelo diferenciado instituído por educadores como Jean Piaget, Paulo Freire e Henri Wallom.

Muitas pesquisas foram realizadas para que essa nova metodologia de ensino fosse adotada e aplicada de maneira a obter resultados satisfatórios na aprendizagem dos alunos, porém, mesmo nos dias de hoje, muitas escolas se deparam com a dificuldade de empregar metodologias inovadoras, ofertando um ensino engessado no qual seus alunos ficam por horas em sala de aula copiando matérias sem ao menos entendê-las. Nesse contexto o professor acaba por tornar-se um líder desempenhando o papel de um ser superior $\mathrm{e}$ acima de seu alunado, que apenas o assiste em aula sem conseguir desenvolver um elo ou uma aproximação para sanar suas dúvidas.

A afetividade é uma temática histórica visto que já nos séculos XVII e XVIII alguns teóricos já realizaram algumas reflexões mencionando em suas discussões a questão juntamente com a da moral. Entre esses teóricos 


\section{Universidade do Extremo Sul Catarinense \\ Revista lbero-Americano de Humanidades, Ciências e \\ Educação \\ Unesc Produção e democratização do conhecimento na lbero-América}

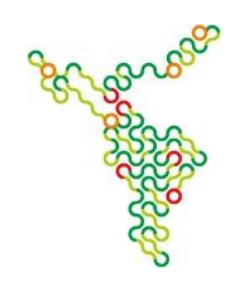

destacam-se Comenius e Rousseau.

Comenius (2002) compara o cérebro na idade infantil a uma esponja apto a receber uma gama de estímulos, deixando claro que esse estímulo inicial seria muito importante para o seu crescimento. Também destaca a importância de o homem aprender os fundamentos de uma sociedade para melhor desfrutar do convívio social, ressaltando que os ensinamentos deveriam ser aplicados de uma forma que não causasse danos ou traumas nos indivíduos.

Dessa forma, o mesmo autor fala de uma educação escolar que, entre outras coisas, leve os estudantes aos mais elevados graus do saber sem dificuldades, sem enfado, sem gritos e pancadas, praticamente brincando e divertindo-se. As escolas com um método mais eficaz, não só poderão manterse em plena florescência como também melhorar indefinidamente (COMENIUS, 2002).

Neste contexto, Lopes (2003, p. 115) constata que,

Numa concepção comeniana, o professor deve desenvolver características próprias e portar-se como um ser escolhido para sua função, de moral íntegra, de exímia inteligência, dedicado exclusivamente ao ensino, pois o pressuposto da questão moral consiste no exemplo de vida.

Comenius cita que já no século XVII constatava-se que o professor obteria melhores resultados desenvolvendo um ensino mais divertido e menos cansativo onde o docente teria uma relação de proximidade, amizade e respeito com seus alunos e não de castigos físicos, maus tratos e punições como era comum na época (COMENIUS, 2002).

Do mesmo modo que Comenius, Rousseau (1994) descreve que no século XVIII, as ações e condutas de um professor diante de seu alunado, ressaltando que o ponto fundamental do sucesso da aprendizagem, seria a relação existente entre eles.

O aluno tem o direito sobretudo de ser amado, e que meios tem um governante de se fazer amar por uma criança a quem ele nada tem a propor senão ocupações contrárias ao seu gosto, a não ser que tenha, por outro lado, poder para conceder-Ihe esporadicamente 


\section{Universidade do Extremo Sul Catarinense \\ Revista Ibero-Americano de Humanidades, Ciências e \\ Educação \\ Unesc Produção e democratização do conhecimento na lbero-América}

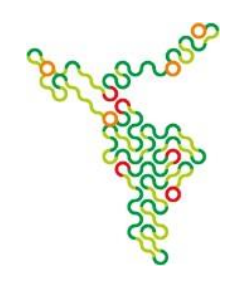

pequenos agrados que quase nada custam em despesas ou perda de tempo, e que não deixam, se oportunamente proporcionados, de causar profunda impressão numa criança, e de ligá-la bastante ao seu mestre. (ROUSSEAU, 1994, p. 24).

O mesmo autor afirma que o professor não deve mostrar-se como um indivíduo rude, severo e zangado com seus alunos sobrecarregando-os com trabalhos difíceis, mas, idealiza em seus estudos um profissional capaz de desenvolver um entrosamento com os educandos a fim de que a tarefa de aprendizagem seja agradável, divertida, que aguce a curiosidade dos alunos de forma que desejem estar ali para buscar a aprendizagem, e não se sintam forçados (ROUSSEAU, 1994).

O psicólogo e educador Jean Piaget é valorizado por vários estudiosos da Psicopedagogia, como Costa (2002) e Battro (1976), por suas teorias de aprendizagem nas quais considera as diferentes fases do desenvolvimento da inteligência na infância. No ano de 1913, o mesmo iniciou suas obras literárias que foram num total de cem, muitas delas voltadas para a Psicopedagogia, considerando que psicologia e educação andam juntas. Em suas obras Piaget destaca que, para acompanhar os processos de ensino aprendizagem no indivíduo, é preciso compreender o meio em que este está inserido e as influencias que esse meio exerce em tal indivíduo.

Piaget mostra que um sujeito inativo e submisso não se desenvolverá apenas com a atuação de um professor, deve ir além disso e apontar que um indivíduo deve atuar em busca do próprio conhecimento. Ele não fornece as respostas de como um professor deve ensinar, mas permite compreender como a criança e ao adolescente aprendem, fornecendo um referencial das possibilidades e limitações dos alunos em idades variadas, indicando que o professor deve respeitar as condições intelectuais dos alunos criando maneiras de melhorar a transmissão dos conhecimentos (COSTA, 2002; BATTRO 1976).

Paulo Freire (1998), educador e filósofo, sempre levantou a bandeira de um ensino dinâmico, com uma relação mais aproximada entre alunos e professores, onde houvesse diálogo e troca de experiências proporcionando assim uma relação estreita e continuamente tendo em vista nunca descartar as 


\section{Universidade do Extremo Sul Catarinense \\ Revista lbero-Americano de Humanidades, Ciências e \\ Educação \\ Unesc Produção e democratização do conhecimento na Ilbero-América}

experiências vivenciadas pelos alunos no seu dia a dia. Dessa forma, criaria um modelo afetivo de educação, onde seriam valorizadas e consideradas as opiniões dos alunos em aula, descartando quaisquer diferenças que pudessem existir, sejam elas de etnia, religião ou classe social. "Assumir-se como ser social e histórico, como ser pensante, comunicante, transformador, criador, realizador de sonhos, capaz de ter raiva porque é capaz de amar." (FREIRE, 1998, p. 46).

Grandes estudiosos como os citados acima, elaboraram muitos estudos sobre a afetividade na educação e como deveria ser aplicada e estimulada por educadores a fim de promover um acréscimo na aprendizagem dos estudantes, porém foi Henri Wallom, um educador francês, que se aprofundou nessa questão desenvolvendo um estudo amplo voltado para a importância da afetividade no processo evolutivo pelo meio educacional.

Para iluminar a questão da afetividade no processo ensino aprendizagem, Henri Wallom (1995) desenvolveu algumas teorias norteadoras em etapas:

- Teoria psicogenética: dá uma importante contribuição para a compreensão do processo de desenvolvimento humano e para o processo ensino aprendizagem. Fornece subsídios para compreender o aluno e o professor, assim como a interação entre eles.

- Considerar em sua teoria o meio no qual o aluno está inserido: considerando a escola o ambiente determinante para o desenvolvimento do aluno e do professor.

- Estabelecer uma relação proveitosa entre psicologia e educação: colocou suas ideias de psicólogo e educador a serviço da reformulação do ensino relacionando as funções afetiva, cognitiva e motora a fim de promover um melhor entendimento emocional dos envolvidos no que se refere ao ensino aprendizagem.

Os domínios funcionais entre os quais se dividirão os estudos das etapas que a criança percorre serão, portanto, os da afetividade, do amor, do conhecimento e da pessoa. (Wallom, 1995, p. 135) considera que: 


\section{Universidade do Extremo Sul Catarinense \\ Revista Ibero-Americano de Humanidades, Ciências e \\ Educação \\ Unesc Produção e democratização do conhecimento na lbero-América}

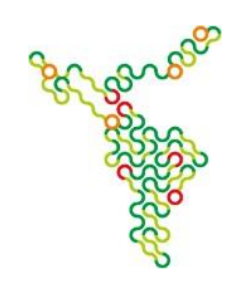

- Os domínios funcionais são construtos que a teoria utiliza para explicar o psiquismo, para explicar o que é inseparável, a pessoa;

- O conjunto afetivo refere-se às funções responsáveis pelos sentimentos e pela motivação;

- O conjunto cognitivo é o conjunto de funções que permite a aquisição e manutenção do conhecimento."

Estudos de Wallom no campo da psicologia pedagógica apontam que a adolescência está no $5^{\circ}$ estágio de classificação de seus estudos, puberdade e adolescência (11 anos em diante). Segundo ele, é uma fase de exploração de si mesmo, busca de uma identidade autônoma, autoafirmação, questionamentos e para isso se submete e se apóia nos pares contrapondo-se aos valores impostos pelos adultos aos quais convive (WALLOM, 1995).

$\mathrm{Na}$ adolescência o recurso principal da aprendizagem, no ponto de vista afetivo, volta a ser a oposição que possibilita a identificação das diferenças entre ideias, sentimentos, valores próprios e do outro, na busca de resolver seus próprios conflitos: Quem sou eu? Quais são meus valores? O que serei no futuro?

O processo ensino aprendizagem nessa etapa, do ponto de vista afetivo, é aquele que permite a expressão e discussão dessas diferenças e que elas sejam levadas em consideração, dentro de um contexto de relacionamento solidário.

\section{A afetividade perante a legislação e como se consolida na sociedade}

Apesar da lei não se referir claramente sobre os laços afetivos, seus diversos enunciados são baseados nos aspectos de convívio familiar, comunitário e dos elos entre os seres, com o objetivo de formar uma pessoa de boa índole.

No artigo 227 da Carta Magna Brasileira se pode extrair os deveres que tem a sociedade, o estado e a família com a criação integral da criança e do adolescente. Apura-se que somente através dos vínculos afetivos é possível cumprir os requisitos da nova ordem jurídico familiar (BRASIL, 1988). Neste contexto, segundo Pereira (2013, p. 46),

$$
\text { Consolida-se família socio afetiva em nossa Doutrina e }
$$




\title{
Universidade do Extremo Sul Catarinense \\ Revista Ibero-Americano de Humanidades, Ciências e \\ Educação \\ Unesc Produção e democratização do conhecimento na lbero-América
}

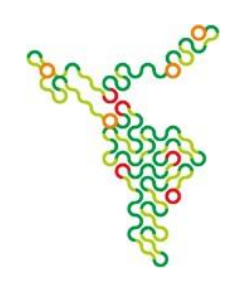

\begin{abstract}
Jurisprudência, uma vez declarada a convivência familiar e comunitária como Direito Fundamental, a não discriminação de filhos, a corresponsabilidade dos pais quanto ao exercício do poder familiar e o núcleo monoparental reconhecido como entidade familiar. Convocando os pais a uma "paternidade responsável", assumiu-se uma realidade familiar concreta onde os vínculos de afeto se sobrepõem a verdade biológica [...]. (PEREIRA 2013, p. 46).
\end{abstract}

Os artigos $3^{\circ}$ e $4^{\circ}$ do Estatuto da Criança e do Adolescente, admitindo a condição de desenvolvimento da criança, reforçam os Princípios Constitucionais capazes de dar os aportes moral, físico, psicológico, mental e social, suficientes para a transposição digna desta fase até a vida adulta. Admitindo esta concepção afetiva nas normas jurídicas brasileiras, deve-se fazer uma reflexão aos artigos 16 e 18 do Estatuto da Criança e do Adolescente, segundo os quais é imperioso zelar pela dignidade dos menores e pô-los a salvo do tratamento desumano, aterrorizante, vexatório ou constrangedor, tarefa esta que cabe ao Estado, à sociedade e à família (BRASIL, 1990).

O Código Civil Brasileiro elenca um rol de deveres de competência dos pais. Em especial, os incisos I e II do artigo 1634, que estabelecem a obrigação que tem o pai de cumprir com as responsabilidades inerentes ao seu papel, com destaque à criação, educação, guarda, companhia e proteção dos filhos (PEREIRA, 2013).

Quando as famílias assumem seus deveres de forma integral conforme determinam as leis, consolida-se uma convivência afetiva entre os seres humanos, cria-se um elo denominado apego, o que gera a sensação de pertencimento ao núcleo no qual nasceram. Esses sentimentos atuam na formação da personalidade da pessoa tendo o meio social no qual ela está inserida, como fator determinante.

Assim sendo, a afetividade vai se consolidando na vida das pessoas através do apego que se cria juntamente com a sensação de pertencimento ao núcleo do qual viemos, sentimentos esses desenvolvidos preliminarmente e que nos proporcionarão segurança diante de nossas decisões futuras. $O$ afeto ou a ausência dele, condição que percebemos em nosso meio familiar, é 


\section{Universidade do Extremo Sul Catarinense \\ Revista Ibero-Americano de Humanidades, Ciências e \\ Educação \\ UneSC Produção e democratização do conhecimento na lbero-América}

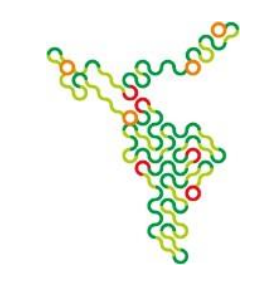

determinante na formação de nossa personalidade atuando para que possamos desenvolver a capacidade de amarmos ou não (WALLON, 2000).

A presença da afetividade em nossa educação é de suma importância e reflete em todas as etapas de nossa trajetória, considerando que, o indivíduo desde o nascimento precisa ter um referencial afetivo seja no pai, na mãe, ou nas pessoas que o cercam. Nesse contexto sabemos que o afeto recebido desde a primeira infância é muito importante para o desenvolvimento de uma vida plena e que a afetividade numa primeira etapa de nossa existência é o fator que demonstra que tipo de seres humanos poderemos nos tornar, sendo a família a maior responsável pelo desenvolvimento. E quando uma pessoa chega à fase adulta, ela deixa transparecer sua essência, refletindo em seu comportamento suas experiências vividas na adolescência e infância.

\section{$3 \mathrm{~A}$ falta de afetividade e suas consequências}

Mesmo existindo leis que asseguram e ressaltam a importância de uma criação afetiva e protetora, essa não é a realidade de muitas crianças e adolescentes. Muitas famílias não conseguem, ou não querem, proteger as crianças e adolescentes de eventos traumáticos que ocorrem em seu meio.

A violência doméstica, separação dos pais, morte de entes queridos, são situações que levam uma criança ou adolescente desenvolver emoções negativas como agressividade, raiva, tornando-as pessoas de difícil convívio familiar e social (BRASÍLIA, 2018).

A infância é a primeira etapa na qual as pessoas passam a interagir em um grupo fora do meio em que vivem, seja em creches, pré-escola ou maternal e é nessa fase que se observa algum prejuízo causado pelo desafeto vivenciado pela criança. Essa criança apresenta problemas de socialização, timidez exagerada, agressividade com colegas, professores, choro descontrolado, dificuldade de fala, dificuldades em lidar com limites que são impostos. Quando esses problemas emocionais não são tratados precocemente, o indivíduo passa para uma nova etapa de sua vida com algumas lacunas, não conseguindo desenvolver o equilíbrio total de suas 


\section{Universidade do Extremo Sul Catarinense \\ Revista Ibero-Americano de Humanidades, Ciências e \\ Educação \\ Unesc Produção e democratização do conhecimento na lbero-América}

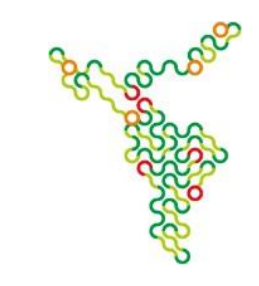

emoções, potencializando casos de depressão, ansiedade e solidão (WALLON, 2000).

A infância e a adolescência compõem o período de construção de identidade de uma pessoa. Para cada indivíduo, a afetividade que recebe do meio em que vive é variável e a tendência é que durante a infância exista maior proximidade dos entes queridos sendo que, na adolescência, o próprio indivíduo busca uma independência de familiares no campo afetivo, porém essa certeza de ser querido é o que dá ânimo para buscar a felicidade (WINNICOTT, 2008).

Sabe-se que pessoas que são pouco afetivas também tiveram uma infância pouco voltada para o afeto. No ambiente escolar, professores com esse perfil não conseguem traçar uma relação consolidada com seus alunos, e quando o aluno possui essa mesma característica, as dificuldades se somam.

\subsection{Tipos de afetividade}

Segundo Paulo Dalgalarrondo (2008), a vida afetiva é a dimensão psíquica que dá cor, brilho e calor a todas as nossas vivências humanas. E segundo este autor, existem cinco tipos básicos de vivências afetivas:

1. Humor - É a forma como está o nosso estado emocional no exato instante, como nos sentimos ao ouvir música, assistindo a um filme, ou pode ser influenciado pelo interior da pessoa (questões hormonais em mulheres).

2. Emoções - É um estado afetivo de curta duração. É uma reação nossa a sensações internas ou externas como moleza, desmaios, desorientações.

3. Sentimentos - Ao contrário das emoções, é um estado afetivo de longa duração. A intensidade é sua principal característica. Existe quando sentimos tristeza, alegria, agressividade ou atração pelo outro.

4. Afetos - O afeto é o "tempero" das emoções e sentimentos. Ele é o impulso dos nossos discursos.

5. Paixão - Intensidade é a melhor denominação para esse sentimento. Ela domina nossa atividade mental, causando a perda da lógica. 


\section{Universidade do Extremo Sul Catarinense \\ Revista Ibero-Americano de Humanidades, Ciências e \\ Educação \\ Unesc Produção e democratização do conhecimento na lbero-América}

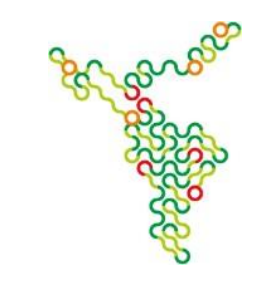

Vale ressaltar que a afetividade é amoral, não distingue o bem ou mal. As consequências dessas experiências é que vai colocá-las nesse tipo de julgamento.

\section{A importância de um ensino com tratamento personalizado}

Todas as pessoas possuem características que as tornam únicas. $\mathrm{Na}$ adolescência essas características se acentuam, por ser um período de transição da fase infantil para a fase adulta, e o adolescente não se enquadra em nenhum padrão sendo considerado criança para algumas coisas e adultos para outras.

$\mathrm{Na}$ esfera educacional essa situação não é diferente, pois o adolescente se sente deslocado quando se depara com dúvidas e dificuldades, ficando intimidado quando precisa de um auxílio específico para sanar suas dúvidas (CAVALCANTE, 2005).

Somente um ensino personalizado promove o verdadeiro conhecimento, pois analisa cada aluno em sua particularidade, conseguindo avaliar suas dificuldades e transpô-las, assim como acentuar suas virtudes. A Base Nacional Comum Curricular (BNCC) aborda essa metodologia, juntamente com o pensamento científico, crítico e criativo, e considera eixos essenciais a serem desenvolvidos ao longo de toda a educação básica.

Nas séries finais do ensino fundamental essa personalização do ensino se faz urgente nos dias atuais, pois nessa fase de vida os estudantes buscam autonomia, sendo que, num contexto educacional, deve ser estimulada e guiada pelo professor que deve desenvolver diferentes estratégias para promover oportunidades para que o aluno faça escolhas ao longo de sua trajetória escolar (LOPES, 2003). Essa metodologia propõe que o aluno seja o principal agente de seu aprendizado. Para proporcionar um ensino dinâmico, o qual explore todo o potencial dos alunos algumas escolas reorganizam seu espaço físico a fim de desenvolver atividades diversas, tanto realizadas em grupos, ou individualmente como debates, experimentações ou exposições.

\subsection{A afetividade No âmbito educacional}




\section{Universidade do Extremo Sul Catarinense \\ Revista lbero-Americano de Humanidades, Ciências e \\ Educação \\ Unesc Produção e democratização do conhecimento na lbero-América}

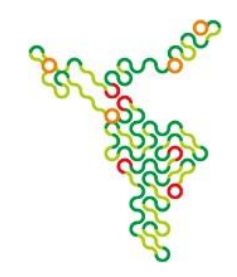

Levando-se em consideração todas as pesquisas realizadas por grandes estudiosos, filósofos, psicólogos e educadores que aprofundaram seus estudos nessa temática, intencionalmente ou não, conclui-se que a afetividade na relação interpessoal na esfera educacional necessita de uma determinação da parte de todos os indivíduos que compõem esse meio. Em todos os estudos realizados, pode-se constatar a importância da sua presença e como ela aumenta a capacidade de obter-se um resultado significativo na aprendizagem.

A educação tradicional, aquela que se apresentava de um modo rígido, onde o professor mantinha um distanciamento de seus alunos, já está perdendo espaço para uma educação formal participativa e inclusiva, baseada em um convívio diário leve e descontraído entre professores e alunos, de forma que o ensino seja transmitido de maneira agradável, estimulante, e não impositiva, isso acontece devido ao reconhecimento de alunos, pais e equipe docente, de que a afetividade deve se fazer presente em todas as situações do nosso cotidiano (OLIVEIRA, 2012) .

Embora exista o reconhecimento da importância de uma relação solidária entre as pessoas no âmbito educacional, essa nova forma de educar, proposta apresentada nos séc. XVII e XVIII, como apontado anteriormente, ainda não é unanimidade, pois, alguns professores, por questões familiares, de valores, ou por ter algumas lacunas nesse aspecto, ainda mantêm uma distância afetiva de seus alunos, não sendo incomum que esses profissionais se deparem com dificuldades quando estão atuando com seus discentes, até mesmo no momento de desenvolver conteúdos em aula (MENEZES, 2006).

Não existindo uma conexão afetiva entre alunos e professores a motivação em aula acaba, e o adolescente direciona-se para outras atividades: conversa, bagunça, brigas, conflitos, gerando atitudes que não acrescentam nada no desenvolvimento humano.

Da mesma maneira que o professor deve apresentar um perfil interessado, afetivo, crítico, que valoriza as qualidades de seus alunos, esse profissional deve se sentir respeitado, querido, sentir satisfação em estar na presença de seus alunos, deve desfrutar de uma conexão afetiva durante 0 


\section{Universidade do Extremo Sul Catarinense \\ Revista Ibero-Americano de Humanidades, Ciências e \\ Educação \\ UneSC Produção e democratização do conhecimento na lbero-América}

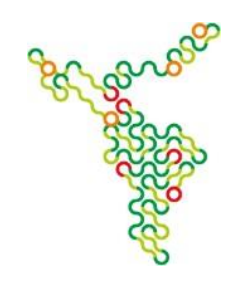

processo de efetivação do conhecimento.

\subsection{Como o professor deve utilizar a afetividade em benefício da educação}

O professor deve proporcionar ao aluno um ambiente de aprendizagem favorável para que ele consiga administrar suas emoções desenvolvendo uma relação entre conhecimento e crescimento emocional para consequentemente desenvolver-se de forma plena.

Considerando a questão da afinidade existente entre as pessoas, é válido salientar que o professor, sendo o líder na situação, é um mediador, não apenas do conhecimento ofertado em sala, mas, nas relações interpessoais. Cabe a ele buscar meios de aproximação entre os alunos ou consigo mesmo, quando essa não existir.

O cuidado com o aluno vai muito além de dar beijinho, elogiar e acarinhar. Muitas vezes o afeto é demonstrado de forma contrária: quando o professor é severo. Se ele é justo e chama atenção de forma respeitosa o aluno passa a admirá-lo e busca não decepcionálo [...] Alunos que se relacionam e se desenvolvem são aqueles que se sentem acolhidos, valorizados por seus talentos e que lidam bem com seus sentimentos. (CAVALCANTE 2005, p. 56).

A aproximação afetiva desenvolve uma confiança entre alunos e professores, estando os educandos na adolescência, que é uma fase de conflitos, permite que se sintam seguros e acolhidos para expor seus questionamentos a respeito dos conteúdos aplicados ou em outras problemáticas vivenciadas. Também favorece para que o professor se sinta compreendido caso necessite fazer aos alunos algum tipo de advertência, considerando que 0 afeto não se caracteriza apenas por carinhos e compreensão, mas por atitudes que também podem repreender um comportamento inadequado, apontando a necessidade de que se corrijam certas atitudes, é também demonstrar interesse em que o outro progrida.

O público adolescente que compõem as séries finais do ensino fundamental, é um grupo onde a presença da afetividade está muito aflorada, e o ambiente escolar é para muitos, o local onde essas emoções se manifestam com maior ímpeto. É ideal que professores estejam aptos para entender e direcionar tais sentimentos, utilizando sua experiência de vida para orientar o 


\section{Universidade do Extremo Sul Catarinense}

Revista Ibero-Americano de Humanidades, Ciências e

Educação

Unesc Produção e democratização do conhecimento na lbero-América

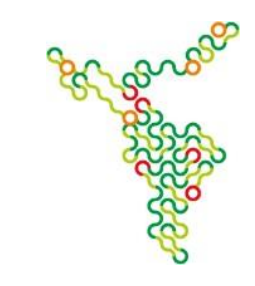

aluno, através do diálogo, e não reprimir tais sentimentos, mas sim canalizálos, direcionando para atividades interessantes, o que favorecerá a aprendizagem.

\section{Metodologia}

Foram analisadas inúmeras bibliografias no âmbito da psicopedagogia, a fim de dissecar o comportamento humano acerca da afetividade e sua relação com 0 aprendizado escolar, dando ênfase às séries finais do Ensino Fundamental.

Inicialmente foram analisadas as obras de autores renomados da psicopedagogia, onde à partir destas pesquisas foram criados tópicos de desenvolvimento dos fatores mais relevantes do estudo, e dentro desses tópicos foram analisadas obras de outros diversos autores dentro de cada temática específica de cada tópico, sendo que houveram estudos de obras de autores de áreas mais abrangentes como o Direito, afim de desenvolver cada tópico com a profundidade necessária de maneira satisfatória.

\section{Resultados}

O primeiro e mais persistente vínculo afetivo é o da mãe com seu filho. É talvez, o único vínculo que persiste até a vida adulta, mesmo depois de separados. É o vínculo que nem mesmo a morte dissocia. Amor é o nome desse vínculo. Portanto se você ama seu filhinho ele estará recebendo um bom princípio. (WINNICOTT, 2008, p. 33).

A formação do primeiro vínculo afetivo se origina na relação entre mãe, pai e bebê, e deste em relação aos pais. A constituição desse vínculo não ocorre de forma instintiva ou automática, requer dedicação, compreensão, tempo e amor.

Significa dizer que o bebê expressa sua insatisfação por meio do choro, que de início é sua única maneira de relacionar-se. Esse choro mobiliza a mãe e ela o interpreta de acordo com seus valores e significados culturais. A interação entre ambos será responsável pelo desencadeamento das funções cognitivas na criança. (WALLON, 1995, p. 37). 


\section{Universidade do Extremo Sul Catarinense \\ Revista lbero-Americano de Humanidades, Ciências e \\ Educação \\ Unesc Produção e democratização do conhecimento na lbero-América}

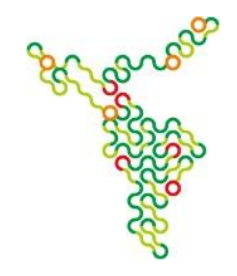

Os pais devem ter ciência que para criar um filho emocionalmente saudável, não requer muitas qualificações, basta que tenham amor e dedicação, isso Ihe garantirá uma base sólida para que cresça com capacidade para enfrentar as diversidades da vida.

Qualquer ser humano que se desenvolva em um lar onde o afeto tenha sua devida importância, virá a ter um desenvolvimento cognitivo satisfatório e bom convívio social quando chegar a fase escolar, com capacidade de dar e receber afeto, demonstrando respeito aos colegas e professores.

\section{Considerações finais}

A afetividade é parte fundamental integrante da personalidade humana e, para além de um sentimento, está presente de maneira muito consistente na evolução psicossocial de cada indivíduo, o que tem consequências de grande escala na organização da sociedade holística. Um ser humano que não tenha recebido afeto de seu núcleo familiar, pode desencadear uma reação em cadeia de decisões desastrosas que podem culminar em uma desordem social, como em casos nos quais esses mesmos indivíduos tenham tendências criminosas causadas pelo destrato na primeira infância e juventude.

No âmbito educacional, esse sentimento e sua importância não poderiam ser tratados diferentemente a não ser de forma a serem valorizados, visando estruturar um ensino de qualidade integrando dinamismo e compreensão, onde o educador atua como uma figura além de um líder que instruí e repassa o conhecimento, como também alguém que se dedica a entender a realidade de cada aluno de maneira personalizada, dando ênfase aos que não tem acesso à sentimentos de amor e afeição dentro do próprio lar.

Quando há uma proximidade por parte do mestre educador com seus educandos, também há uma compreensão melhor de suas dificuldades de aprendizagem e o docente tem maior facilidade em identificar o foco de seu ensinamento e escolher o método mais proveitoso, baseando-se em pesquisas de vários estudiosos e teóricos da psicopedagogia, muitos deles abordados e comentados neste presente artigo.

As dificuldades para criar-se laços com os discentes são acentuadas 


\section{Universidade do Extremo Sul Catarinense \\ Revista lbero-Americano de Humanidades, Ciências e \\ Educação \\ UnesC Produção e democratização do conhecimento na lbero-América}

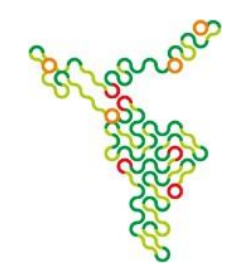

durante o período da puberdade à adolescência, onde os alunos tendem a afastar-se da influência dos adultos, até mesmo de sua própria família, afim de viverem experiências transformadoras que irão auxiliá-los na busca de sua própria identidade, porém em muitas ocasiões essas experiências são de cunho danoso, e sem a supervisão de um responsável esses adolescentes podem afastar-se, até mesmo de maneira permanente, das atividades benéficas, principalmente de caráter escolar e acadêmico.

Nesse cenário, o educador deve acionar o auxílio do restante do corpo docente, afim de reunir esforços para criar vínculos de afeto com os alunos que desenvolvem comportamento de níveis mais problemáticos, em alguns casos até mesmo fora do âmbito escolar, mesmo que haja dificuldades nessa interação, fazendo contato com a família e outras instituições que têm por finalidade o amparo dos jovens que se encontram em situações adversas.

$O$ jovem precisa entender a situação de risco na qual se encontra, e a família por diversas vezes não presta a assistência necessária ao desenvolvimento saudável de caráter desse indivíduo, portanto o corpo docente, como parte constituinte na evolução das gerações que se formam, pode vir a atuar também no âmbito particular dos relacionamentos interpessoais deste cidadão, pois em diversos casos são a estrutura melhor preparada na vida do mesmo para guiá-lo ao caminho do conhecimento e da vivência saudável em sociedade.

Desta forma, o afeto atua como fator principal na construção da confiança deste jovem para que o mesmo possa compreender que se faz necessária uma mudança estrutural em seu estilo de vida.

Mesmo para os casos onde os jovens não se encontram em situação precária e/ou de desafeto familiar, o afeto no âmbito escolar entra como fator decisivo na melhora da aprendizagem do aluno que desenvolve aptidão até mesmo para a matéria evidenciada pelo docente no qual o aluno adquiriu essa relação. Ele vê maior facilidade em questionar e sanar suas dúvidas ao docente, pois o mesmo terá a certeza de que receberá um retorno atencioso e convalescente. Espera-se, com esta revisão, contribuir para uma reflexão sobre 


\section{Universidade do Extremo Sul Catarinense \\ Revista Ibero-Americano de Humanidades, Ciências e \\ Educação \\ UnesC Produção e democratização do conhecimento na lbero-América}

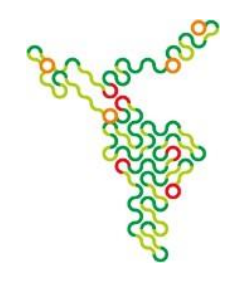

a importância da afetividade nas séries finais do ensino fundamental

\section{REFERÊNCIAS}

BATTRO, Antônio M. O pensamento de Jean Piaget. Rio de Janeiro: Forense Universitária, 1976.

BRASIL. Constituição da República Federativa do Brasil. Brasília: DF, Senado, 1998.

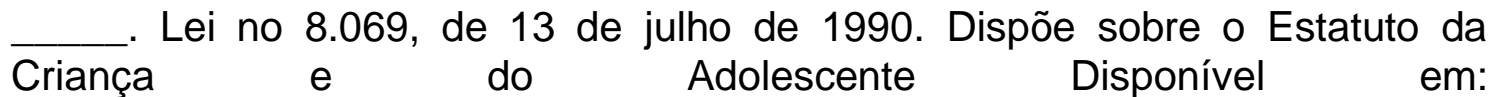 <http://www.planalto.gov.br/ccivil_03/LEIS/L8069.htm\#art266>. Acesso em 25 jul. 2019.

BRASÍLIA. Ministério dos Direitos Humanos. Secretaria Nacional de Proteção dos Direitos da Criança e Adolescente. 2018. Disponível em: <https://www.mdh.gov.br/biblioteca/crianca-e-adolescente/violencia-contracriancas-e-adolescentes-analise-de-cenarios-e-propostas-de-politicas-publicas2.pdf>. Acesso em 25 jul. 2019.

CAVALCANTE, Meire. Uma sala confortável e inclusiva. Nova Escola, São Paulo, n. 188, p. 45, dez 2005.

, Meire. Como criar uma escola acolhedora. Nova Escola. São Paulo: Abril, no. 180, p. 52-57, março de 2005.

COMENIUS, Jan Amos. Didática Magna. 3. ed. - São Paulo: Martins Fontes, 2002.

COSTA, Maria Luiza Andreozzi da. Piaget e a intervenção psicopedagógica. São Paulo: Olho d'água, 2002.

DALGALARRONDO, Paulo. Psicopatologia e semiologia dos transtornos mentais. Porto Alegre: Artmed, 2008.

OLIVEIRA, S. E.; et al. (2012). "Inclusão social: professores preparados ou não?", Polêmica - Revista Eletrônica, vol. 11, núm. 2, pp. 1-9. Rev. Polêmica, v. 11, n. 2, p. 314-323, 2012.

FREIRE, Paulo. Pedagogia da Autonomia: Saberes necessários à prática educativa. $7^{\mathrm{a}} \mathrm{ed}$. Rio de Janeiro: Paz e Terra, 1998.

GADOTTI, M. Convite a leitura de Paulo Freire. São Paulo: Scipione, 1999.

LOPES, Edson Pereira. O conceito de teologia e pedagogia na Didática 


\section{Universidade do Extremo Sul Catarinense}

Revista Ibero-Americano de Humanidades, Ciências e

Educação

UneSC Produção e democratização do conhecimento na lbero-América

Magna de Comenius. São Paulo: Mackenzie, 2003.

MENEZES, M. C. B. Desenvolvimento cognitivo e afetivo: implicações no processo de alfabetização e letramento. Dissertação de mestrado, Faculdade de educação, Universidade Estadual de Maringá, 2006.

PEREIRA, Caio Mario da Silva. Instituições de Direito Civil: Direito de Família. $21^{\underline{a}}$ ed. Rio de Janeiro: Forense, 2013.

ROUSSEAU, Jean Jaques. Projeto para a educação do Senhor de SainteMarie. Edição bilingue. Paraula, 1994.

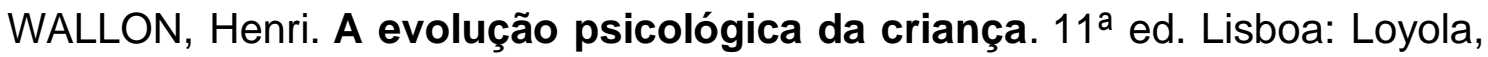
2000.

WINNICOTT, Donald Woods. A criança e seu mundo. Trad. Álvaro Cabral. Rio de Janeiro: Editora LTC, 2008. 